\title{
PReS-FINAL-2097: Evaluation of gait in children with juvenile idiopathic arthritis
}

\author{
SN Baydogan ${ }^{1 *}$, E Tarakcl $^{2}$, O Kasapcopur ${ }^{3}$ \\ From 20th Pediatric Rheumatology European Society (PReS) Congress \\ Ljubljana, Slovenia. 25-29 September 2013
}

\begin{abstract}
Introduction
Juvenile idiopathic arthritis (JIA) causes pain that may lead to posture and movement modifications and arouses muscular imbalance with reduced range of motion in the affected joints. Clinical assessment of the gait is difficult in children, because of the complexity and rapidity of movement. In children with JIA, the gait pattern is further complicated by subtle compensatory gait alterations in response to joint pain and limb deformity.
\end{abstract}

\section{Objectives}

To examine gait in children with joint involvement in knee who suffered from juvenile idiopathic arthritis (JIA) with video-based observation gait analysis.

\section{Methods}

30 patients $($ male $=9$, female $=21)$ were included in the study. Kinematic and time distance gait parameters were measured using a 10-meter walkway with separated $4 \mathrm{~cm}$ stripes in white and black color and a video camera. Sagittal plane views of cases (right and left, two views) and the foreground and background views of walking (two views), a total of 4 views were recorded. After observing views in the normal speed, views were observed by using slowed down frame-by-frame viewing and the stop function. Time distance parameters and motion deviations in stance phase of gait were examined.

\section{Results}

The mean age was $9.63 \pm 2.76$ years (range 2-18 years). The mean disease duration was $4.41 \pm 2.16$ years (range 1-9 years). Patient population consisted of 11 patients with romatoid factor $(+)$ polyarticular arthritis, 4 patients with romatoid factor (-) polyarticular arthritis, 12 patients

Division of Physiotherapy and Rehabilitation, Faculty of Health Science, Istanbul University, Istanbul, Turkey

Full list of author information is available at the end of the article with oligoarticular arthritis, and 3 patients psoriatic arthritis subtype. The mean of walking speed, step length, double step length and cadence were $0.51 \mathrm{~m} / \mathrm{s}, 0.49 \pm 0.07 \mathrm{~m}$, $0.99 \pm 0.14 \mathrm{~m}$ and $101 \pm 25.33 \mathrm{steps} / \mathrm{min}$ respectively. The most noticeable changes in range of motion was increase of hip internal rotation(76.7\%) and knee flexion(80\%). Also, genu valgus incidence was $40 \%$, genu varum was $20 \%$ and pes valgus was $36.7 \%$.

\section{Conclusion}

Gait is a parameter that should be considered in children with JIA. This study reported that the time-distance variables of children with JIA were decreased according to healthy peers in the literature. In the same time, we observed some gait deviations during the stance phase in lower extremity in children with JIA. These deviations are moderate or severe increase of hip adduction, hip internal rotation and knee flexion. Also we found genu valgus and pes valgus in static posture. We have identified these problems may relate to response to pain, avoidance harm to joints and some structural changes in joints.

\section{Disclosure of interest}

None declared.

\section{Authors' details \\ ${ }^{1}$ Division of Physiotherapy and Rehabilitation, Faculty of Health Science, Istanbul University, Istanbul, Turkey. ${ }^{2}$ Division of Physiotherapy and Rehabilitation, Faculty of Health Science, Istanbul University, Istanbul. ${ }^{3}$ Department of Pediatric Rheumatology, Medical Faculty of Cerrahpasa, Istanbul University, Istanbul, Turkey.}

Published: 5 December 2013

doi:10.1186/1546-0096-11-S2-P109

Cite this article as: Baydogan et al:: PReS-FINAL-2097: Evaluation of gait in children with juvenile idiopathic arthritis. Pediatric Rheumatology 2013 11(Suppl 2):P109.
C Biomed Central

(c) 2013 Baydogan et al.; licensee BioMed Central Ltd. This is an Open Access article distributed under the terms of the Creative Commons Attribution License (http://creativecommons.org/licenses/by/2.0), which permits unrestricted use, distribution, and reproduction in any medium, provided the original work is properly cited. The Creative Commons Public Domain Dedication waiver (http://creativecommons.org/publicdomain/zero/1.0/) applies to the data made available in this article, unless otherwise stated. 